\section{BMJ Paediatrics Open}

\title{
Risk factors of non-typhoidal Salmonella gastroenteritis in hospitalised young children: a case-control study
}

\author{
Pei Yee Woh (D) , ${ }^{1}$ May Pui Shan Yeung, ${ }^{1}$ E Anthony S Nelson, ${ }^{2}$ \\ William Bernard III Goggins ${ }^{1}$
}

To cite: Woh PY, Yeung MPS, Nelson EAS, et al. Risk factors of non-typhoidal Salmonella gastroenteritis in hospitalised young children: a case-control study. BMJ Paediatrics Open 2021;5:e000898. doi:10.1136/ bmjpo-2020-000898

- Additional material is published online only. To view, please visit the journal online (http://dx.doi.org/10.1136/ bmjpo-2020-000898).

Received 1 October 2020 Revised 15 November 2020 Accepted 21 November 2020

Check for updates

(c) Author(s) (or their employer(s)) 2021. Re-use permitted under CC BY-NC. No commercial re-use. See rights and permissions. Published by BMJ.

${ }^{1}$ Jockey Club School of Public Health and Primary Care, Faculty of Medicine, The Chinese University of Hong Kong, Shatin, Hong Kong Special Administrative Region 2Department of Paediatrics, Faculty of Medicine, The Chinese University of Hong Kong, Shatin, Hong Kong Special Administrative Region

Correspondence to Professor William Bernard III Goggins; wgoggins@cuhk. edu.hk

\section{ABSTRACT}

Objective To explore risk factors associated with nontyphoidal Salmonella gastroenteritis in young children in Hong Kong.

Design A case-control study.

Setting Paediatrics wards at three public hospitals in Hong Kong.

Participants Cases were children aged above 30 days to below 5 years hospitalised for gastroenteritis at three public hospitals in Hong Kong with culture confirmed nontyphoidal Salmonella infection. Controls were age-matched ( \pm 2 months) children admitted for a reason other than gastroenteritis.

Main outcomes measures A face-to-face interview by using standardised questionnaire on exposures 3 days prior to illness. Adjusted OR (aORs) and $95 \%$ Cls were calculated using multivariable logistic regression.

Results A total of 102 cases and 204 age-matched controls were included in the analysis. Multivariable logistic regression revealed that having food purchased from places other than a supermarket, that is, from wet market/restaurant/farm (aOR, 2.64; $95 \% \mathrm{Cl}, 1.03$ to 6.77 ; $\mathrm{p}=0.044$ ) was a significant risk factor for non-typhoidal Salmonella infection. Having a household member with gastroenteritis symptoms (aOR, 2.03; $95 \% \mathrm{Cl}, 0.94$ to 4.39 ; $\mathrm{p}=0.072$ ) was of borderline significance and playing at a children's indoor playroom was a protective factor (aOR, $0.28 ; 95 \% \mathrm{Cl}, 0.09$ to $0.85 ; \mathrm{p}=0.024$ ).

Conclusions Consumption of food purchased from places other than a supermarket was the identified determinant factor for non-typhoidal Salmonella gastroenteritis in Hong Kong. Parents/caregivers should be alerted to this risk when choosing foods for their young children. The protective effect of playing in an indoor playroom could be confounded by socioeconomic factors and further investigation is required to better understand its potential implication. There was some support for person-to-person transmission and good family hygiene needs to be emphasised.

\section{INTRODUCTION}

Non-typhoidal Salmonella is one of the main bacterial causes of gastroenteritis that responsible for a considerable proportion of diarrheal morbidity and mortality in children below 5 years, ${ }^{1}$ and accounts for 95.1 million cases $(95 \%$ uncertainty interval 41.6 to

\section{What is known about the subject?}

Salmonella infections are often acquired through ingestion of contaminated food of animal origin and contact with infected animals or contaminated environments.

- Previous studies have identified some risk factors of paediatric salmonellosis due to different lifestyle, dietary habits and environmental condition at different geographical regions.

- Recognition of the principal source of transmission of Salmonella infection in children is important for public health advocacy to reduce salmonellosis burden.

\section{What this study adds?}

Consumption of food purchased from places other than supermarkets was the main modifiable risk factor for childhood salmonellosis in Hong Kong.

- Data suggest that not closing toilet bowl before flushing and type of domestic flooring were potential risk factors that should be considered to reduce childhood salmonellosis.

184.8), 50771 deaths (2824-129736), and 3.10 million disability-adjusted life years (0.39-7.39), according to Global Burden of Diseases, Injuries, and Risk Factors Study 2017. ${ }^{2-4}$ Although most salmonellosis cases are self-limiting, some invasive Salmonella strains can cause serious bacteriaemia and systemic infections in vulnerable populations including young children, the elderly and those with underlying diseases or immunosuppression. $^{5}$

Salmonella infections are often acquired through ingestion of contaminated food of animal origin and contact with infected animals or contaminated environments. ${ }^{5}$ Sources of salmonellosis in young children may differ from those in older populations. Identified potential risk factors of salmonellosis in young children include having a child 
riding in a shopping cart next to meat or poultry, ${ }^{78}$ exposure to reptiles, ${ }^{710}$ attending a childcare centre with infected children, ${ }^{7}$ consumption of powdered infant formula, ${ }^{7}$ eating eggs, undercooked ground beef, chicken or animal produce, ${ }^{79^{11-17}}$ family transmission of Salmonella ${ }^{112}$ and travelling abroad. ${ }^{79}$ These risk factors of paediatric salmonellosis may vary due to different lifestyle, dietary habits and environmental condition at different geographical regions.

Recognition of sources of transmission of Salmonella infection in children is important for public health advocacy to reduce salmonellosis exposure. Therefore, we conducted an age-matched case-control study to explore potential risk factors of non-typhoidal Salmonella gastroenteritis in children aged below 5 years in Hong Kong, a high-income, densely populated city with a sub-tropical climate.

\section{METHODS}

\section{Study design and setting}

This study was conducted in three public hospitals in Hong Kong (Prince of Wales Hospital, Alice Ho Miu Ling Nethersole Hospital and United Christian Hospital). Recruitment of cases and controls commenced at the same time on 15 April 2019 and ended on 4 November 2019.

\section{Participants}

Gastroenteritis refers to the inflammation of mucus membrane of the gastrointestinal tract with presentation of diarrhoea or vomiting. ${ }^{18}$ Cases were patients aged from 30 days to below 5 years who were admitted to one of the study hospitals for gastroenteritis during the study period with onset of diarrhoea or vomiting $\leq 14$ days before admission. Patients who contracted gastroenteritis of any cause after admission were excluded. Parents/guardians of potentially eligible patients were invited to participate during their ward visit within 72 hours of attendance. The laboratory-confirmed Salmonella results from stool specimens collected from patients with gastroenteritis were retrieved from the Clinical Management System (a computerised database used in all public hospitals in Hong Kong).

Controls were patients aged 30 days to below 5 years who were admitted for a condition other than gastroenteritis (ie, non-gastroenteritis controls), recruited from the same paediatric ward of the study hospitals. We aimed to recruit two controls for each case, matched on age (up to 2 months younger or 2 months older than the case).

Participating parents/guardians of cases and controls were invited for face-to-face interviews at the study hospitals with a standardised questionnaire (see online supplemental appendix 1) modified for local use. ${ }^{19}$ All participants provided written informed consent. Questionnaires collected data on exposures, sociodemographic and clinical symptoms. Medical information including admission details, final diagnoses and laboratory results were obtained from the patient's medical records and the Clinical Management System.

\section{Sample size}

Sample size was based on $80 \%$ power, $5 \%$ significance level, two controls per case and a percentage of exposure in controls $30 \%$. To detect an OR of 2.1, 95 cases and 190 controls were required based on exposures from previous studies (egg consumption ${ }^{9}$ because this risk factor is frequently found to be associated with increased risk of Salmonella infections).

\section{Exposures}

The exposures of interest were household living conditions, childcare attendance, breastfeeding, powdered infant formula, consumption and source of specific high-risk foods (chicken eggs, duck eggs, preserved eggs, chicken, pork, beef, seafood, sushi, honey and congee), food outlet and grocery shopping exposure, family hygiene practices, animal contact, intrafamilial transmission of Salmonella, child's mobility/social events and travel.

\section{Statistical analysis}

Association between exposures and childhood salmonellosis were estimated using ORs and 95\% CIs. Univariate analyses were performed and variables with omnibus $\mathrm{p}<0.30$ were then included in multivariable logistic regression analysis to simultaneously control for any effects of confounding. Backward elimination was used to build the multivariable model, with likelihood ratio test used to assess significance and $\mathrm{p}<0.05$ considered statistically significant. Some exposures were considered as potential confounders for other exposures. We tested for multicollinearity and excluded variables with high correlation with milk diet (both breastmilk and powdered infant formula) and food consumption (pork, honey and sushi). Some variables with missing values were excluded, these includes cleaning method of feeding equipment, sterilising method of feeding equipment, measured water temperature before preparation, source of chicken eggs, source of chicken, source of pork, source of honey, source of congee. As the ORs for food sourced from restaurants and farm were $>1$, for example, they showed higher risk than for food purchased from the supermarkets, and that the numbers in school was very small and no ORs were shown (see online supplemental table S1) so we excluded food sourced from school from the single group 'wet market/restaurant/farm' and compared with supermarket and none group. Comparison of categorical variables between cases and controls was performed with $\chi^{2}$ tests or Fisher's exact test where appropriate. The Mann-Whitney test was used to compare the distribution of continuous variables.

\section{Patients and public involvement}

In this study, neither patient nor public was involved in the study proposal development, design and analysis of the study.

\section{RESULTS}

Of the total 643 patients recruited, $241(37.5 \%)$ were potential gastroenteritis patients and $402(62.5 \%)$ were 
643 Total number of patients recruited

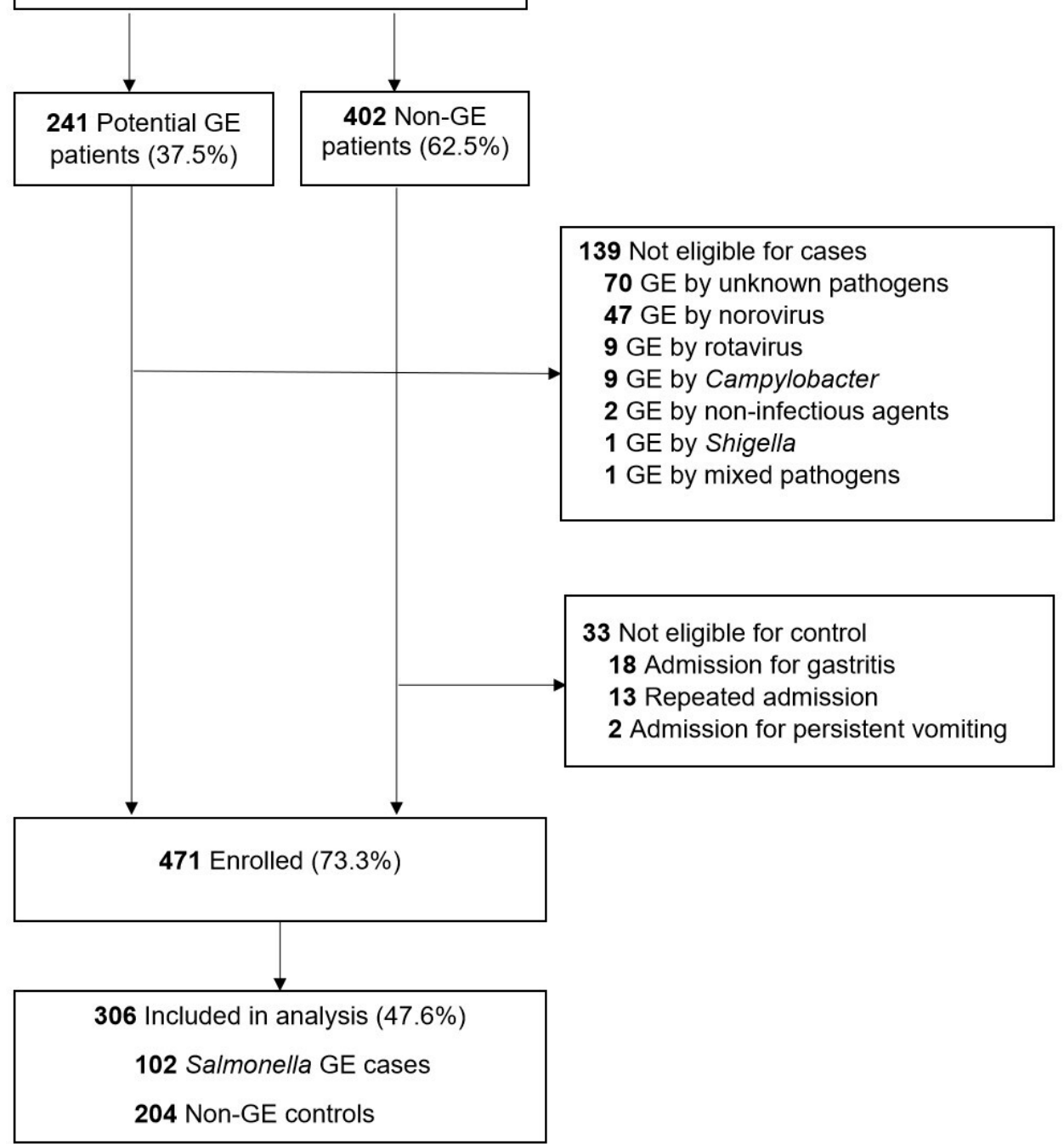

Figure 1 Flowchart of cases and controls recruitment.GE; gastroenteritis.

non-gastroenteritis patients. In the group of patients with gastroenteritis, 139 were excluded as their gastroenteritis was caused by other infectious agents, including norovirus, rotavirus, Campylobacter and Shigella, or because no causal agent was found. In the group of patients without gastroenteritis, 33 were excluded due to repeated admissions $(13 / 33)$, gastritis $(18 / 33)$ or persistent vomiting (2/33). Among the 471 eligible subjects, 204 nongastroenteritis controls (reasons for hospitalisation shown in online supplemental table S3) were matched to the 102 Salmonella positive cases and included in the final analyses (figure 1).

The baseline demographic indicates that over half of the patients were male $(57.2 \%)$ with median age of 20 months (table 1). A plurality of the children was living in a household where family members whose working environment was related to food and drink $(14.4 \%)$, patients $(6.5 \%)$ or children $(4.9 \%)$. Patients with Salmonella infection were marginally younger (median 19 months) than controls (median 20 months). Compared with the controls, the cases did not differ significantly with regards to age, gender, household nature of work, household income level and maternal education. For the 102 Salmonella cases, 46 (45.1\%) were serogroup B, 8 (7.8\%) were serogroup C, 47 (46.1\%) were serogroup D and 1 was ungroupable (table 2). The laboratory serology further classified 15 isolates and 7 isolates into Salmonella Enteritidis and $S$. Typhimurium, respectively. The proportion of laboratory cultured-confirmed diagnosis for Salmonella hospitalisation was the highest in June $(25.5 \%$, 26/102) and the lowest in April (4.9\%, 5/102) (figure 2); however, no strong association of monthly distribution of Salmonella infections was observed. We noticed a strong association between Salmonella serotypes distribution by children age $\left(\chi^{2}=20.35, \mathrm{df}=6, \mathrm{p}=0.002\right)$, where children aged $<2$ years were likely to be infected by Salmonella group B while children aged $>2$ years were likely to be infected by Salmonella group D (figure 3).

Concerning to clinical symptoms, when compared with controls, the patients with Salmonella infections were more 
Table 1 Baseline, demographic and clinical symptoms of non-typhoidal Salmonella gastroenteritis cases and non-Salmonella gastroenteritis controls aged $<5$ years from three public hospitals in Hong Kong

\begin{tabular}{|c|c|c|c|c|}
\hline & All, $n=306$ & Cases, $n=102$ & Controls, n=204 & $P$ value \\
\hline \multicolumn{5}{|l|}{ Demographic } \\
\hline Age on admission (months), median (range) & $20(1-59)$ & $19(2-59)$ & $20(1-59)$ & 0.96 \\
\hline \multicolumn{5}{|l|}{ Gender, n (\%) } \\
\hline Male & $175(57.2)$ & $59(57.8)$ & $116(56.9)$ & 0.87 \\
\hline Female & $131(42.8)$ & $43(42.2)$ & $88(43.1)$ & \\
\hline \multicolumn{5}{|l|}{ Household nature of work, n (\%) } \\
\hline Contact with food and drink & $44(14.4)$ & $15(14.7)$ & $29(14.2)$ & 0.70 \\
\hline Contact with patient & $20(6.5)$ & $6(5.9)$ & $14(6.9)$ & \\
\hline Contact with children & $15(4.9)$ & $3(2.9)$ & $12(5.9)$ & \\
\hline None of these contacts & $227(74.2)$ & $78(76.5)$ & $149(73.0)$ & \\
\hline \multicolumn{5}{|l|}{ Household income level, HKD\$, n (\%) } \\
\hline$<20000$ & $75(24.5)$ & $25(24.5)$ & $50(24.5)$ & 0.59 \\
\hline 20000-39999 & $122(39.9)$ & $37(36.3)$ & $85(41.7)$ & \\
\hline$>39999$ & $109(35.6)$ & $40(39.2)$ & $69(33.8)$ & \\
\hline \multicolumn{5}{|l|}{ Maternal education, n (\%) } \\
\hline Junior secondary and below & $49(16.0)$ & $16(15.7)$ & $33(16.2)$ & 0.99 \\
\hline Senior secondary & $127(41.5)$ & $42(41.2)$ & $85(41.7)$ & \\
\hline Tertiary and above & $130(42.5)$ & $44(43.1)$ & $86(42.2)$ & \\
\hline \multicolumn{5}{|l|}{ Symptoms and severity } \\
\hline Diarrhoea, n (\%) & $160(52.3)$ & $96(94.1)$ & $64(31.4)$ & $<0.001^{*}$ \\
\hline Vomiting, n (\%) & $117(38.2)$ & $44(43.1)$ & $73(35.8)$ & 0.21 \\
\hline Fever, n (\%) & $282(92.2)$ & $101(99.0)$ & $181(88.7)$ & $0.002^{*}$ \\
\hline Abdominal pain, n (\%) & $74(24.2)$ & $47(46.1)$ & 27 (13.2) & $<0.001^{*}$ \\
\hline Blood in stools, n (\%) & $42(13.7)$ & $36(35.3)$ & $6(2.9)$ & $<0.001^{*}$ \\
\hline Mucus in stools, $\mathrm{n}(\%)$ & $75(24.5)$ & $57(55.9)$ & $18(8.8)$ & $<0.001^{*}$ \\
\hline Length of hospital stay (days), median (IQR) & 3 (2 to 5) & 3 (2 to 5 ) & $3(1,5)$ & 0.20 \\
\hline
\end{tabular}

*Significant at $\mathrm{p}<0.05$.

HKD\$, Hong Kong dollars.

likely to experienced abdominal pain $(46.1 \%, 47 / 102)$ and diarrhoea $(94.1 \%, 96 / 102)$ with stools containing mucus $(55.9 \%, 57 / 102)$ and blood $(35.3 \%, 36 / 102)$. Fever was developed nearly in all cases $(101 / 102,99.0 \%)$. Although these are the common clinical presentations of Salmonella infections, we found a higher rate of these symptoms compared with a similar case-control study in Vietnam by Thompson et $a l^{20}$ that reported a lower rate of fever $(75.4 \%)$, abdominal pain $(16.9 \%)$, bloody

\begin{tabular}{lc}
\hline $\begin{array}{l}\text { Table } 2 \\
(\mathrm{n}=102)\end{array}$ & Summary of Salmonella isolated from cases \\
\hline & $\mathbf{n}$ \\
\hline Salmonella Typhimurium & $7(6.9 \%)$ \\
\hline Salmonella Enteritidis & $15(14.7 \%)$ \\
Salmonella group B (including S. Typhimurium) & $46(45.1 \%)$ \\
Salmonella group C & $8(7.8 \%)$ \\
Salmonella group D (including S. Enteritidis) & $47(46.1 \%)$ \\
Ungroupable & $1(1.0 \%)$ \\
\hline
\end{tabular}

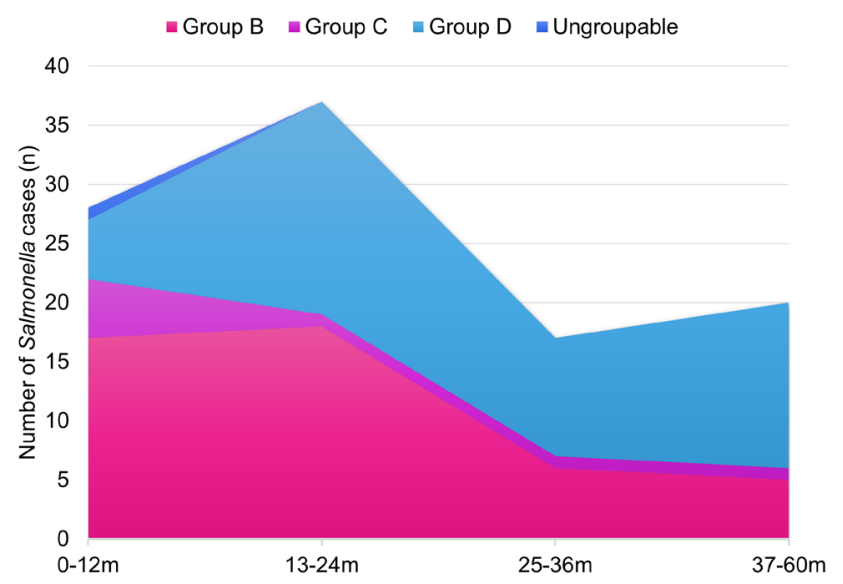

Figure 2 Distribution of non-typhoidal Salmonella infections by child's age (months). 


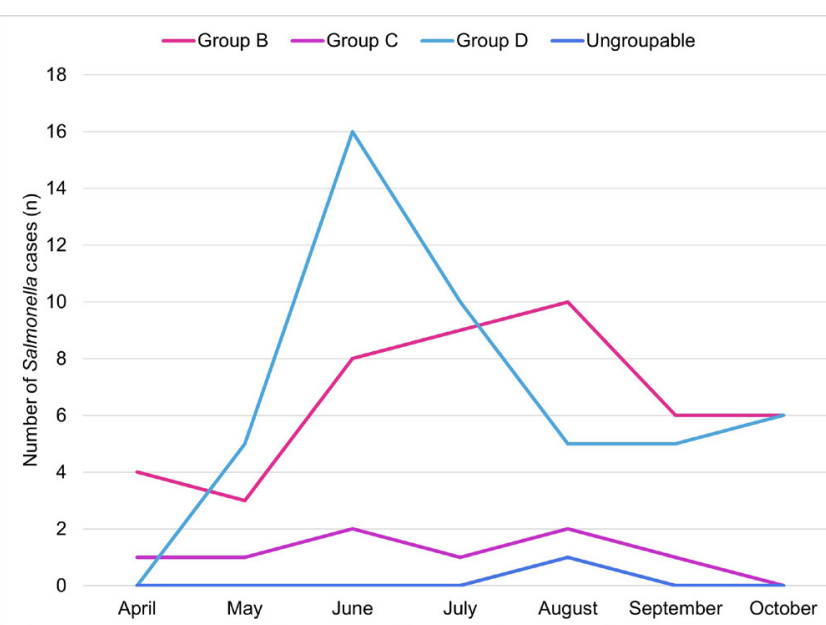

Figure 3 Monthly distribution of non-typhoidal Salmonella hospitalisations. diarrhoea $(7.8 \%)$ and mucoid diarrhoea $(33.8 \%)$. We noticed that the length of hospital stay $(\mathrm{p}=0.20)$ was not significantly different between cases (median 3 days, IQR 2-5) and controls (median 3 days, IQR 1-5).

After controlling for the factors (source of high-risk food, playing at indoor playroom, having household member with gastroenteritis symptoms, riding child inside shopping cart while buying raw chicken, type of flooring (wooden/tile), milk diet (breastmilk/powdered infant formula/combination of both), closing lid of toilet bowl before flushing and playing at playground) found to have omnibus $\mathrm{p}$ value $<0.30$ in the univariate analysis (online supplemental table S2), the final multivariable logistic regression analysis revealed that having food purchased from wet market/restaurant/farm was significantly associated with increased Salmonella infection risk (adjusted OR (aOR), 2.64; 95\% CI, 1.03 to 6.77; $\mathrm{p}=0.044$ ) (table 3). Having a household member with gastroenteritis symptoms (aOR, 2.03; 95\% CI, 0.94 to

\begin{tabular}{|c|c|c|c|c|}
\hline \multirow[b]{2}{*}{ Risk factors } & \multicolumn{2}{|l|}{ Univariate analysis } & \multicolumn{2}{|c|}{ Multivariable analysis } \\
\hline & OR $(95 \% \mathrm{Cl})$ & $P$ value & aOR $(95 \% \mathrm{Cl})$ & $P$ value \\
\hline \multicolumn{5}{|l|}{ Source of high-risk food } \\
\hline Wet market/restaurant/farm & 2.41 (1.01 to 5.74$)$ & $0.047^{*}$ & 2.64 (1.03 to 6.77$)$ & $0.044^{*}$ \\
\hline Supermarket & $0.64(0.17$ to 2.45$)$ & 0.51 & 0.73 (0.18 to 2.98$)$ & 0.67 \\
\hline None & Ref & - & Ref & - \\
\hline \multicolumn{5}{|c|}{ Played at children indoor playroom } \\
\hline Yes & 0.27 (0.09 to 0.79$)$ & $0.017^{*}$ & 0.28 (0.09 to 0.85$)$ & $0.024^{*}$ \\
\hline No & Ref & - & Ref & - \\
\hline \multicolumn{5}{|c|}{ Household member with gastroenteritis symptoms } \\
\hline Yes & $2.52(1.20$ to 5.28$)$ & $0.014^{*}$ & 2.03 (0.94 to 4.39$)$ & 0.072 \\
\hline No & Ref & - & Ref & - \\
\hline \multicolumn{5}{|c|}{ Carried child inside shopping cart while buying raw chickens } \\
\hline Yes & 3.06 (0.50 to 18.61$)$ & 0.23 & $1.85(0.29$ to 11.85$)$ & 0.52 \\
\hline No & Ref & - & Ref & - \\
\hline \multicolumn{5}{|l|}{ Type of flooring in child's room } \\
\hline Wooden & 1.54 (0.55 to 4.34$)$ & 0.41 & $1.45(0.44$ to 4.80$)$ & 0.54 \\
\hline Tile & $2.08(0.81$ to 5.37$)$ & 0.13 & $1.74(0.58$ to 5.21$)$ & 0.32 \\
\hline Carpet/cement/others & Ref & - & Ref & - \\
\hline \multicolumn{5}{|l|}{ Milk diet 3 days prior to illness } \\
\hline Breastmilk only & 0.68 (0.23 to 2.00$)$ & 0.48 & $0.80(0.25$ to 2.53$)$ & 0.70 \\
\hline Formula milk only & $0.99(0.54$ to 1.81$)$ & 0.97 & $1.00(0.52$ to 1.86$)$ & 0.95 \\
\hline Breastmilk and formula milk & $0.30(0.08$ to 1.14$)$ & 0.078 & 0.38 (0.09 to 1.53$)$ & 0.17 \\
\hline None & Ref & - & Ref & - \\
\hline \multicolumn{5}{|c|}{ Closed lid of toilet bowl before flushing } \\
\hline Yes & 0.77 (0.48 to 1.25$)$ & 0.29 & $0.78(0.47$ to 1.29$)$ & 0.33 \\
\hline No & Ref & - & Ref & - \\
\hline \multicolumn{5}{|l|}{ Played at playground } \\
\hline Yes & 0.74 (0.45 to 1.22$)$ & 0.24 & 0.64 (0.38 to 1.10$)$ & 0.11 \\
\hline No & Ref & - & Ref & - \\
\hline
\end{tabular}

*Significant at $\mathrm{p}<0.05$

aOR, adjusted OR.; 
4.39; $\mathrm{p}=0.072$ ) was a borderline significant risk factor of Salmonella infection. Playing at a children's indoor playroom was inversely associated with Salmonella infection risk (aOR, 0.28; 95\% CI, 0.09 to $0.85 ; \mathrm{p}=0.024)$.

\section{DISCUSSION}

Non-typhoidal Salmonella gastroenteritis continues to be an important child health issue that often requires hospitalisation in Hong Kong. To the best of our knowledge, this is one of relatively few studies exploring risk factors for salmonellosis in young children in Hong Kong and worldwide. $^{7-17}$

Living in a household where food was purchased from places other than a supermarket, including wet markets, restaurants or farms was associated with 2.64 times increased risk of Salmonella infection relative to those who only purchased these foods from a supermarket. Our result is similar to that of a study conducted in Ho Chi Minh city, Vietnam, which found that children households which regularly purchased meat and vegetables at outdoor markets had a significantly increased risk of Salmonella, but did not specify the reference group..$^{20}$ It is interesting to note that the increased risk for Salmonella infection among those consuming food from wet markets was found both in Hong Kong, a high-income city, and Vietnam a low middle-income country. Although wet markets are an important source of affordable food for low-income families in Hong Kong, they have also been shown in other studies to have a higher prevalence of foodborne pathogens as compared with supermarkets. ${ }^{21-23} \mathrm{~A}$ recent local study on the hygienic state of meat cutting boards in wet markets revealed a significant presence of hospital nosocomial pathogens such as Klebsiella pneumoniae and pathogens with antibiotic resistant genes. ${ }^{24}$ It could be due to a limited supply of potable water to rinse animal carcasses and the frequent recycling of used water in wet markets as compared with supermarkets. Also, the less packaging of meat or uncovered carcasses in wet markets may facilitate the transmission of foodborne pathogens disseminated by flies. In addition, lack of proper lavatory and handwashing facilities may lead to a higher chance of contamination. It is possible that there was transmission of foodborne pathogens from food handlers to customers during meal preparation and serving at the hawker centres located inside the wet markets, as food handlers have been identified as key players in food contaminations due to unsatisfactory personal hygiene in Hong Kong, ${ }^{25}$ Ireland $^{26}$ and other Asian countries. ${ }^{27-30}$ Some studies have demonstrated higher levels of Salmonella contamination in animal carcasses such as chicken and beef sold in wet markets compared with supermarkets. ${ }^{23} 3132$ The present study was conducted during the wet and hot summer months where high ambient temperature and humidity may favour the growth of Salmonella ${ }^{33}$ resulting in a higher risk of animal carcasses being contaminated with Salmonella.
Living in a domestic environment with household members having gastroenteritis symptoms was associated with a two-fold increased risk of Salmonella infections in young children. This finding agrees with studies from Taiwan ${ }^{11}$ and the USA, ${ }^{34}$ which found an 18 -fold and a 13-fold higher risk of childhood salmonellosis, respectively. To prevent such transmission, family members with gastroenteritis symptoms, need to be reminded about the importance of hand washing after going to the toilet and before handling solid or liquid food for children.

The protective association of salmonellosis with playing in indoor playrooms was an unexpected finding. It is possible that this finding is confounded to higher sociodemographic status, as apartment buildings with indoor play spaces tend to be expensive in Hong Kong. This potential protective factor has not been reported elsewhere and requires further investigation to better understand its potential implication.

Our study explored some other potential risk factors not reported elsewhere where a protective trend was noted when families reported closing the toilet lid before flushing. Previous studies have shown that flushing the toilet with the lid open enables Salmonella bioaerosol to survive in bathrooms and toilets for several weeks and that this practice contaminates toilet seats, flush handle, toilet bowl water, bathroom wall and floor. ${ }^{35}{ }^{36}$ Children may be at increased risk since they exhibit behaviours such as touching, biting or crawling on these bioaerosolcontaminated objects. Further studies may confirm whether improving hygiene in bathrooms and toilets can prevent salmonellosis to children and other family members.

Having a child riding in the shopping cart while buying raw chicken was not associated with increased of Salmonella infection risk. Two US studies ${ }^{78}$ showing this factor increased risk of childhood salmonellosis with OR 3.2 (95\% CI, 2.1 to 5.1$)^{7}$ and OR 15.5 (95\% CI, 9.2 to 26.1$)^{8}$ respectively. The lack of association in our study may reflect that this practice is not common in Hong Kong. Shopping carts are frequently handled by numerous users and not routinely disinfected in supermarkets ${ }^{37}$ and have high microbiological loads on handles and basket-child seats. Children may come into direct contact with Salmonella through touching contaminated packaging of raw chicken meat contaminated with Salmonella $^{38} 39$ suggesting that parents should prevent their child touching raw products and use hand sanitizer to wipe shopping carts.

Our study revealed that living in a household environment especially child's room equipped with tile flooring and wooden flooring were associated with increased Salmonella risk, which agrees with an experimental study in the USA demonstrated that over $99 \%$ of $S$. Typhimurium were transferred from tile to food after $5 \mathrm{~s}$ of exposure to tile. ${ }^{40}$ The finding further revealed that contamination of $S$. Typhimurium from carpet to food was very low $(<0.5 \%)$ as compared with wood and tile $(5 \%-68 \%)$. Children are at a higher risk of bacterial pathogens contamination 
from the floor because of their mobility activities, for example, crawling, touching or biting toys/food dropped and picked up from unsanitary floor. Although most non-typhoidal Salmonella infections in human are foodborne ${ }^{6}$ environmental contacts with households flooring materials contaminated with Salmonella are potentially risky. ${ }^{40}{ }^{41}$ It is noted that choosing the appropriate floor surface for child room is important, as type of flooring materials may influence the bacterial pathogen composition that could impact the air quality of the household environment. ${ }^{42-47}$ Some studies have compared bacterial contamination on a variety of floor material types, that is, 'soft' surface for carpet and 'hard or bare' surface for vinyl tiles; however, the results of these findings were not consistent. Foarde and Berry, ${ }^{43}$ Rice et $a l^{41}$ and Anderson et $a t^{2}$ reported higher microbiological counts of Salmonella, Escherichia coli, Staphylococcus aureus and Pseudomonas aeruginosa on carpets, but Rylander et $a t^{46}$ and Harris et $a t^{44}$ reported higher surface bacterial levels on vinyl tiles than on carpets. Another study reported that $S$. aureus are more likely to colonise vinyl tile than ceramic tiles floor in a Turkish hospital. ${ }^{47}$ Such risk factor, although not statistically significant in present study, it warrants a more stringent household preventive measures such as regular disinfection and cleaning of floor to minimise the chances of getting Salmonella infection in young children.

\section{Strengths and limitations}

This case-control study was carried out between April and November 2019 covering entire summer which favour the growth of Salmonella thus higher recruitment chances of gastroenteritis cases caused by Salmonella than other microorganisms. More importantly, the chances of Salmonella cases overestimation are minimal as diagnosis of hospitalisation was based on International Classification of Diseases, Ninth Revision, Clinical Modification coding and clinical discharge summary of Salmonella infections is frequently referring to laboratory-confirmed report in Clinical Management System.

There were several limitations in our study, the most important of which is that the overall study numbers were small and as such some of the subgroup analyses resulting in a lack of statistical power in the multivariable analysis, for example patients who had food sourced from schools need to be removed from the other locations that is, wet markets, restaurants and farms. Nonetheless, childcare attendance could have excluded because children were on summer break during the study period. Seasonalactivities and selection of presumed potential risk factors should be carefully considered to better questionnaire design and modification for local use. Our study was conducted among children aged above 30 days and below 5 years so the results cannot be extrapolated to population older than 5 years, but it should be noted that younger children are much more susceptible than older group to salmonellosis and most hospital admission for Salmonella are in young children. The current was hospitalbased so the findings can only be generalised to children with more severe symptoms that seek medical attention and this may reflect the prevalence of the non-typhoidal salmonellosis in community. Another limitation was information bias. Questions were designed and relied on parents or guardian's report of their children condition in the 3 days prior to illness and therefore some might have forgotten the sickness incident during the interview (memory issues) leading to misreporting on the occurrence of Salmonella gastroenteritis that can influences the direction of the outcomes of cases/controls (recall bias) thus underestimate the true ORs or association of causal effect. Besides, it should be noted that wrong assumptions about the form of relationship between confounder and illness can lead to wrong conclusions of exposure effects.

\section{CONCLUSION}

The main modifiable risk factor was giving young children foods purchased from sources other than a supermarket, that is, wet markets, restaurants or farms and parents and caregivers can be alerted to this risk when choosing foods for their young children. There was some support for person-to-person transmission being an important source of Salmonella infections that result in hospitalisations. Family members with gastroenteritis symptoms should avoid close contact with young children and practice good hand hygiene in the domestic setting.

Acknowledgements We thank the contribution of parents or guardians who participated in this study. We also thank the doctors, nurses and administrative staff from the Department of Paediatrics for their assistance in recruiting participants at Prince of Wales Hospital, Alice Ho Miu Ling Nethersole Hospital and United Christian Hospital. In addition, we recognise the efforts of individuals who contributed to data collection with compensation. We are also grateful to Dr Lee Hau Man who assisted in Clinical Management System checking at Alice Ho Miu Ling Nethersole Hospital and to Dr Fung Po Gee Genevieve who assisted in ethics application and subject recruitment at United Christian Hospital.

Contributors PYW drafted the manuscript and all authors helped to locate and check the information accuracy in this manuscript where possible and then reviewed the manuscript prior to submission. PYW and GBW conducted the statistical analysis and had full access to all data in the study and take responsibility for the integrity of the data and the accuracy of the analysis.

Funding This work was supported by Chung Chi College Student Helper Award Scheme 2019 (project no. AF00008) and part of unrestricted grants from Division of Biostatistics (project no. 7103510 and 7051838), The Chinese University of Hong Kong.

Competing interests None declared.

Patient consent for publication Not required.

Ethics approval Ethics approvals were granted by the Institutional Review Boards of the Joint Chinese University of Hong Kong-New Territories East Cluster Clinical Research Ethics Committee (Ref: CRE-2018.416) and Kowloon Central/Kowloon East Research Ethics Committee (Ref: KC/KE-19-0116/ER-2).

Provenance and peer review Not commissioned; externally peer reviewed.

Data availability statement Data are available on reasonable request. All relevant data are available on reasonable request by emailing the corresponding author.

Supplemental material This content has been supplied by the author(s). It has not been vetted by BMJ Publishing Group Limited (BMJ) and may not have been peer-reviewed. Any opinions or recommendations discussed are solely those of the author(s) and are not endorsed by BMJ. BMJ disclaims all liability and responsibility arising from any reliance placed on the content. Where the content includes any translated material, BMJ does not warrant the accuracy and reliability of the translations (including but not limited to local regulations, clinical guidelines, 
terminology, drug names and drug dosages), and is not responsible for any error and/or omissions arising from translation and adaptation or otherwise.

Open access This is an open access article distributed in accordance with the Creative Commons Attribution Non Commercial (CC BY-NC 4.0) license, which permits others to distribute, remix, adapt, build upon this work non-commercially, and license their derivative works on different terms, provided the original work is properly cited, appropriate credit is given, any changes made indicated, and the use is non-commercial. See: http://creativecommons.org/licenses/by-nc/4.0/.

ORCID iD

Pei Yee Woh http://orcid.org/0000-0001-5950-7883

\section{REFERENCES}

1 GBD 2016 Diarrhoeal Disease Collaborators. Estimates of the global, regional, and national morbidity, mortality, and aetiologies of diarrhoea in 195 countries: a systematic analysis for the global burden of disease study 2016. Lancet Infect Dis 2018:18:1211-28.

2 GBD 2017 Disease and Injury Incidence and Prevalence Collaborators. Global, regional, and national incidence, prevalence, and years lived with disability for 354 diseases and injuries for 195 countries and territories, 1990-2017: a systematic analysis for the global burden of disease study 2017. Lancet 2018;392:1789-858.

3 GBD 2017 DALYs and HALE Collaborators. Global, regional, and national disability-adjusted life-years (DALYs) for 359 diseases and injuries and healthy life expectancy (HALE) for 195 countries and territories, 1990-2017: a systematic analysis for the global burden of disease study 2017. Lancet 2018;392:1859-922.

4 GBD 2017 Causes of Death Collaborators. Global, regional, and national age-sex-specific mortality for 282 causes of death in 195 countries and territories, 1980-2017: a systematic analysis for the global burden of disease study 2017. Lancet 2018;392:1736-88.

5 Eng S-K, Pusparajah P, Ab Mutalib N-S, et al. Salmonella : a review on pathogenesis, epidemiology and antibiotic resistance. Front Life Sci 2015;8:284-93.

6 Od FN, Penha Filho R, Barrow P, et al. Sources of human nontyphoid salmonellosis: a review. Braz J Poultry Sci 2010;12:01-11.

7 Jones TF, Ingram LA, Fullerton KE, et al. A case-control study of the epidemiology of sporadic Salmonella infection in infants. Pediatrics 2006;118:2380-7.

8 Patrick ME, Mahon BE, Zansky SM, et al. Riding in shopping carts and exposure to raw meat and poultry products: prevalence of and factors associated with, this risk factor for Salmonella and Campylobacter infection in children younger than 3 years. $J$ Food Prot 2010;73:1097-100.

9 Marcus R, Varma JK, Medus C, et al. Re-Assessment of risk factors for sporadic Salmonella serotype Enteritidis infections: a casecontrol study in five FoodNet sites, 2002-2003. Epidemiol Infect 2007;135:84-92.

10 Mermin J, Hutwagner L, Vugia D, et al. Reptiles, amphibians, and human Salmonella infection: a population-based, case-control study. Clin Infect Dis 2004;38 Suppl 3:S253-61.

11 Chen C-J, Wu F-T, Hsiung CA, et al. Risk factors for Salmonella gastroenteritis in children less than five years of age in Taiwan. Pediatr Infect Dis J 2012;31:e239-43.

12 Delarocque-Astagneau E, Bouillant C, Vaillant V, et al. Risk factors for the occurrence of sporadic Salmonella enterica serotype Typhimurium infections in children in France: a national case-control study. Clin Infect Dis 2000;31:488-92.

13 Friesema IHM, Schimmer B, Ros JA, et al. A regional Salmonella enterica serovar Typhimurium outbreak associated with raw beef products, The Netherlands, 2010. Foodborne Pathog Dis 2012;9:102-7.

14 Hennessy TW, Cheng LH, Kassenborg $\mathrm{H}$, et al. Egg consumption is the principal risk factor for sporadic Salmonella serotype Heidelberg infections: a case-control study in FoodNet sites. Clin Infect Dis 2004;38 Suppl 3:S237-43.

15 Kimura AC, Reddy V, Marcus R, et al. Chicken consumption is a newly identified risk factor for sporadic Salmonella enterica serotype Enteritidis infections in the United States: a case-control study in FoodNet sites. Clin Infect Dis 2004;38 Suppl 3:S244-52.

16 MacDougall L, Fyfe M, Mclntyre L, et al. Frozen chicken nuggets and strips--a newly identified risk factor for Salmonella Heidelberg infection in British Columbia, Canada. J Food Prot 2004;67:1111-5.

17 Yang X, Jin K, Yang F, et al. Nontyphoidal Salmonella gastroenteritis in Baoshan, Shanghai, China, 2010 to 2014: an etiological surveillance and case-control study. J Food Prot 2017;80:482-7.

18 Chow CM, Leung AK, Hon KL. Acute gastroenteritis: from guidelines to real life. Clin Exp Gastroenterol 2010;3:97-112.
19 Queensland Government. Salmonella infection 1996-2015. Available: http://disease-control.health.qld.gov.au/condition/782/salmonellainfection [Accessed December 1, 2018].

20 Thompson CN, Phan VTM, Le TPT, et al. Epidemiological features and risk factors of Salmonella gastroenteritis in children resident in Ho Chi Minh City, Vietnam. Epidemiol Infect 2013;141:1604-13.

21 Ghafir Y, China B, Korsak N, et al. Belgian surveillance plans to assess changes in Salmonella prevalence in meat at different production stages. J Food Prot 2005;68:2269-77.

22 Odwar JA, Kikuvi G, Kariuki JN, et al. A cross-sectional study on the microbiological quality and safety of raw chicken meats sold in Nairobi, Kenya. BMC Res Notes 2014;7:627.

23 Scheinberg J, Doores S, Cutter CN. A microbiological comparison of poultry products obtained from farmers' markets and supermarkets in Pennsylvania. J Food Saf 2013;33:259-64.

24 Lo MY, Ngan WY, Tsun SM, et al. A field study into Hong Kong's wet markets: raised questions into the hygienic maintenance of meat contact surfaces and the dissemination of microorganisms associated with nosocomial infections. Front Microbiol 2019;10:2618.

25 Center for Health Protection. Scientific committee on enteric infections and foodborne diseases: review of nontyphoidal Salmonella food poisoning in Hong Kong, 2011. Available: https:// www.chp.gov.hk/files/pdf/review_of_nontyphoidal_salmonella_food poisoning_in_hong_kong_r.pdf [Accessed 20 Jan 2020].

26 Moreb NA, Priyadarshini A, Jaiswal AK. Knowledge of food safety and food handling practices amongst food handlers in the Republic of Ireland. Food Control 2017:80:341-9.

27 Gong S, Wang X, Yang Y, et al. Knowledge of food safety and handling in households: a survey of food handlers in mainland China. Food Control 2016;64:45-53.

28 Sun Y-M, Wang S-T, Huang K-W. Hygiene knowledge and practices of night market food vendors in Tainan City, Taiwan. Food Control 2012;23:159-64.

29 Woh PY, Thong KL, Behnke JM, et al. Evaluation of basic knowledge on food safety and food handling practices amongst migrant food handlers in Peninsular Malaysia. Food Control 2016;70:64-73.

30 Woh PY, Thong KL, Lim YAL, et al. Microorganisms as an indicator of hygiene status among migrant food handlers in Peninsular Malaysia. Asia Pac J Public Health 2017;29:599-607.

31 Khan AS, Georges K, Rahaman S, et al. Prevalence and serotypes of Salmonella spp. on chickens sold at retail outlets in Trinidad. PLOS One 2018;13:e0202108.

32 Shafini AB, Son R, Mahyudin NA, et al. Prevalence of Salmonella spp. in chicken and beef from retail outlets in Malaysia. Int Food Res J 2017;24:437-49.

33 Wang P, Goggins WB, Chan EYY. Associations of Salmonella hospitalizations with ambient temperature, humidity and rainfall in Hong Kong. Environ Int 2018;120:223-30.

34 Rowe SY, Rocourt JR, Shiferaw B, et al. Breast-feeding decreases the risk of sporadic salmonellosis among infants in FoodNet sites. Clin Infect Dis 2004;38 Suppl 3:S262-70.

35 Ajibade VA, Aboloma RI, Oyebode JA. Survival and antimicrobial resistance of Salmonella enterica isolated from bathrooms and toilets following salmonellosis in some homes in Ado-Ekiti. Res $J$ Agric Biol Sci 2010;6:637-40.

36 Barker J, Bloomfield SF. Survival of Salmonella in bathrooms and toilets in domestic homes following salmonellosis. J Appl Microbiol 2000:89:137-44.

37 Carrascosa C, Sanjuán E, Millán R, et al. Is the use of supermarket trolleys microbiologically safe? study of microbiological contamination. J Appl Anim Res 2019;47:17-23.

38 Harrison WA, Griffith CJ, Tennant D, et al. Incidence of Campylobacter and Salmonella isolated from retail chicken and associated packaging in South Wales. Lett Appl Microbiol 2001;33:450-4.

39 Wong $\mathrm{T}$, Janet Whyte R, Joyce Cornelius $\mathrm{A}$, et al. Enumeration of Campylobacter and Salmonella on chicken packs. Br Food J 2004:106:651-62.

40 Dawson P, Han I, Cox M, et al. Residence time and food contact time effects on transfer of Salmonella Typhimurium from tile, wood and carpet: testing the five-second rule. J Appl Microbiol 2007;102:945-53.

41 Rice DH, Hancock DD, Roozen PM, et al. Household contamination with Salmonella enterica. Emerg Infect Dis 2003:9:120-2.

42 Anderson RL, Mackel DC, Stoler BS, et al. Carpeting in hospitals: an epidemiological evaluation. J Clin Microbiol 1982;15:408-15.

43 Foarde K, Berry M. Comparison of biocontaminant levels associated with hard vs. carpet floors in nonproblem schools: results of a year long study. J Expo Anal Environ Epidemiol 2004;14 Suppl 1:S41-8. 
44 Harris DD, Pacheco A, Lindner AS. Detecting potential pathogens on hospital surfaces: an assessment of carpet tile flooring in the hospital patient environment. Indoor Built Environ 2010;19:239-49.

45 Rashid T, Vonville H, Hasan I, et al. Mechanisms for floor surfaces or environmental ground contamination to cause human infection: a systematic review. Epidemiol Infect 2017;145:347-57.
46 Rylander R, Myrbäck KE, Verner-Carlson B, et al. Bacteriological investigation of wall-to-wall carpeting. Am J Public Health 1974;64:163-8.

47 Yazgi $\mathrm{H}$, Uyanik $\mathrm{MH}$, Ayyildiz A. Comparison of slime-producing coagulase-negative Staphylococcus colonization rates on vinyl and ceramic tile flooring materials. J Int Med Res 2009;37:668-73. 